\title{
Mannose-binding lectin activation is associated with the progression of diabetic nephropathy in type 2 diabetes mellitus patients
}

\author{
Kedan Cai ${ }^{1,2,3,4 \#}$, Yanhong Ma ${ }^{1,2,3 \#}$, Junni Wang ${ }^{1,2,3}$, Wanyun $\mathrm{Nie}^{1,2,3}$, Junmin Guo ${ }^{1,2,3,5}$, \\ Minqiao Zhang ${ }^{1,2,3,6}$, Yi Yang ${ }^{1,2,3}$, Jianghua Chen ${ }^{1,2,3}$, Fei Han ${ }^{1,2,3}$
}

${ }^{1}$ Kidney Disease Center, the First Affiliated Hospital, College of Medicine, ${ }^{2}$ Institute of Nephrology, Zhejiang University, Hangzhou, China; ${ }^{3}$ Key Laboratory of Kidney Disease Prevention and Control Technology, Hangzhou, China; ${ }^{4}$ Hwa Mei Hospital, University of Chinese Academy of Sciences, Ningbo, China; ${ }^{5}$ The Second People's Hospital of Jinhua, Jinhua, China; ${ }^{6}$ Department of Nephrology, the First People's Hospital of Xiangshan, Ningbo, China

Contributions: (I) Conception and design: F Han, K Cai, Y Ma; (II) Administrative support: F Han, J Chen; (III) Provision of study materials or patients: F Han, K Cai, Y Ma; (IV) Collection and assembly of data: F Han, K Cai, Y Ma, J Wang, W Nie, J Guo, M Zhang, Y Yang; (V) Data analysis and interpretation: F Han, K Cai, Y Ma; (VI) Manuscript writing: All authors; (VII) Final approval of manuscript: All authors.

\#These authors contributed equally to this work.

Correspondence to: Fei Han. 79 Qingchun Road, Hangzhou 310003, China. Email: hanf8876@zju.edu.cn.

Background: We aimed to investigate whether mannose-binding lectin (MBL) activation contributed to the progression of diabetic nephropathy (DN), and its role in predicting the renal prognosis of DN.

Methods: Seventy-seven patients who received renal biopsy in the First Affiliated Hospital, College of Medicine, Zhejiang University between August 2013 and September 2016 were enrolled in the study. These patients were followed up until the endpoint of end-stage renal disease (ESRD) or the last follow-up time of August 31, 2018. They were divided into ESRD group (33 patients) and non-ESRD group (44 patients). Their baseline characteristics and MBL levels (serum and urine) were compared between groups. The correlation between single nucleotide polymorphisms (SNPs) of the MBL2 gene and renal outcomes was also analyzed.

Results: The median (interquartile ranges) of serum and urine MBL levels were significantly higher in ESRD group than those in non-ESRD group $[2,783.75$ (1,244.28, 3,837.07) vs. 1,141.60 (652.67, $3,188.44) \mathrm{ng} / \mathrm{mL}, \mathrm{P}=0.016 ; 1.02(0.43,2.05)$ vs. 0.27 (0.04, 0.58) ng/mg, $\mathrm{P}<0.01$, respectively]. Both univariate and multivariate Cox analysis showed that serum $\mathrm{MBL}>1,108.75 \mathrm{ng} / \mathrm{mL}$ (stratified by maximum Youden index) was an independent predictor for ESRD [hazard ratio (HR) $=4.164,95 \%$ confidence interval (CI): 1.601-10.833, $\mathrm{P}=0.003 ; \mathrm{HR}=4.644$, 95\% CI: 1.320-16.337, $\mathrm{P}=0.017$; respectively]. For the patients with rs1800450 SNPs of MBL2 gene, patients with homozygous genotype (GG) had higher serum MBL level (median 2,963.52 ng/mL) compared with those with heterozygous genotype (GA) (median $665.38 \mathrm{ng} / \mathrm{mL}$ ) $(\mathrm{P}<0.001)$. MBL2 rs1800450 GA genotype was an independent protective factor for ESRD with a HR of 0.485 (95\% CI: 0.237-0.991; $\mathrm{P}=0.047$ ).

Conclusions: Activation of MBL contributed to the progression of DN. The rs 1800450 SNP of the MBL2 gene may be of value in predicting the progression to ESRD in DN patients.

Keywords: Diabetic nephropathy (DN); mannose-binding lectin (MBL); single nucleotide polymorphisms (SNPs)

Submitted Jan 28, 2020. Accepted for publication Sep 06, 2020.

doi: 10.21037/atm-20-1073

View this article at: http://dx.doi.org/10.21037/atm-20-1073 


\section{Introduction}

Diabetes accounts for $30-50 \%$ of chronic kidney disease (CKD) and the proportion is increasing rapidly (1). Renal inflammation is involved in the pathogenesis and progression of diabetic nephropathy (DN) (2-5). Mannosebinding lectin (MBL) is a natural immune soluble medium that was shown to be involved in the development of DN $(6,7)$. Zheng et al. reported that MBL might act in the activation of the complement mediated renal interstitial injury (8). Li et al. found that MBL and factor Bb levels in serum and urine were correlated with the severity of DN (9). Also, MBL deposit was found in renal pathology in patients with type 2 diabetes mellitus (DM) in different populations (10).

In this study, we aimed to determine whether MBL contributes to the progression of DN and to identify its correlation with the endpoint of end-stage renal disease (ESRD) in DN patients; single nucleotide polymorphisms (SNPs) of MBL2 gene were also studied. We present the paper in accordance with the STROBE reporting checklist (available at http://dx.doi.org/10.21037/atm-20-1073).

\section{Methods}

\section{Patients}

We enrolled 77 type $2 \mathrm{DM}$ patients who were admitted into our center from August 2013 to September 2016. All of them received a renal biopsy, and serum and urine sample acquisition at the time of renal biopsy. This retrospective cohort study has adhered to the STROBE guidelines for cohort studies. The diagnosis of type $2 \mathrm{DM}$ or DN was according to the criteria proposed by the American Diabetes
Association (ADA) in 2017 (11) or the criteria by the Renal Pathology Society (RPS) in 2010 (12), respectively. Patients complicated with other kidney diseases, active infections, severe liver dysfunction, under immunosuppressive therapy, kidney allograft recipients, reaching ESRD before renal biopsy, with incomplete baseline data, or lost in follow-up were excluded. The flow chart is shown in Figure 1. The number of cases during the study period determined the sample size. The research protocols were conformed to the provisions of the Declaration of Helsinki (as revised in 2013) and were approved by the Ethics Committee of the First Affiliated Hospital of Medical School of Zhejiang University (No. 2017243). All patients were informed consent.

The baseline characteristics of the patients including the demographic data, physical examination, the comprehensive chemical panel on the day of the renal biopsy were collected from the hospital information system. We kept following up each patient until a confirmed ESRD or the last followup time of August 31, 2018. The data on outcomes was obtained from outpatient medical records, the website of Zhejiang Medical Quality Control and Evaluation for Dialysis, and telephone follow-ups. ESRD was defined as an estimated glomerular filtration rate (eGFR, calculated by CKD-EPI formula) lower than $15 \mathrm{~mL} / \mathrm{min} / 1.73 \mathrm{~m}^{2}$ or requirement of renal replacement therapy.

\section{Blood and urine samples processing}

Blood and urine samples were collected on the same day of renal biopsy. Serum and blood mononuclear cells were separated and stored in aliquots at $-80{ }^{\circ} \mathrm{C}$ until usage.

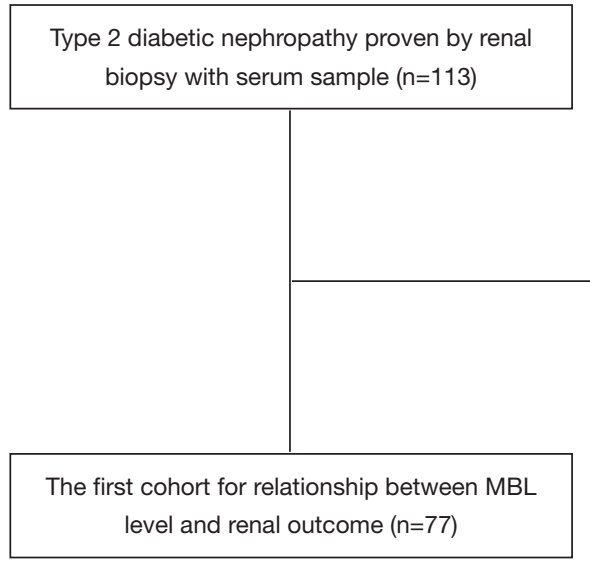

Coexistence with other renal diseases $(n=17)$ Coexistence with active infection $(n=1)$ Liver dysfunction $(\mathrm{n}=2)$

Taking steroid or immune-suppressant $(n=3)$

Renal transplantation $(\mathrm{n}=2)$

Insufficient main clinical information $(n=11)$

Figure 1 The flow chart of the patient recruitment in this study. MBL, mannose-binding lectin. 
Serum samples for complement measurement were thawed at room temperature for 1 hour, and then centrifuged at $3,500 \mathrm{rpm}$ for $5 \mathrm{~min}$ at $4{ }^{\circ} \mathrm{C}$ in a Thermo Scientific ${ }^{\mathrm{TM}}$ Heraeus $^{\mathrm{TM}}$ Multifuge ${ }^{\mathrm{TM}} \mathrm{X} 1$ Centrifuge (ThermoFisher Scientific, Rockford, IL, USA).

\section{Quantification of MBL levels}

Serum or urine MBL levels were measured by enzyme linked immunosorbent assay (ELISA). Commercial ELISA kits (R\&D Systems, USA) were used according to the manufacturer's instructions. Samples were thawed rapidly at $37^{\circ} \mathrm{C}$ and then kept on ice before measuring to ensure no additional complement activation. Repeated freeze-thaw cycles were avoided.

\section{Renal bistology}

Each biopsy was routinely processed for light microscopy, immunofluorescence, and electron microscopy. The pathological classification and scores were evaluated based upon the 2010 RPS criteria. Renal pathological findings were categorized by glomerular lesions (I, IIa, IIb, III, IV), interstitial fibrosis and tubular atrophy (IFTA) $[0,1,2,3]$, interstitial inflammation $[0,1,2]$ and arteriosclerosis $[0,1,2]$.

\section{Cell sample processing}

Cell samples were thawed, transferred to ethylenediaminetetraacetic acid (EDTA) tubes, remained at room temperature for $30 \mathrm{~min}$, and then centrifuged at 3,500 rpm for 5 min at $4{ }^{\circ} \mathrm{C}$ in a Thermo Scientific ${ }^{\mathrm{TM}}$ Heraeus $^{\mathrm{TM}}$ Multifuge ${ }^{\mathrm{TM}} \mathrm{X} 1$ Centrifuge (Thermo-Fisher Scientific, Rockford, IL, USA). The supernatant was disposed with erythrocyte lysis and then centrifuged again at 3,500 rpm for $10 \mathrm{~min}$ to collect blood mononuclear cells.

\section{SNP selection and genotyping}

SNPs in the MBL2 gene are associated with variation in quantity and/or function of serum MBL. The polymorphism is determined by the co-occurrence of three promoter variants (H/L, rs11003125; X/Y, rs7096206; and $\mathrm{P} / \mathrm{Q}$, rs7095891) and one exon 1 variant (B, rs1800450) (13). DNA from DN patients was sequenced using the sanger two-way sequencing (model 3730; Applied BioSystems). Primer sequences for $M B L 2$ were forward primer (5'-GTTTTCTAATTGCCAGTGG-3') and reverse primer (5'-CAAATAGGACATCAGTCTCC-3').

\section{Statistical analysis}

All statistical analyses were performed with SPSS software, version 19.0 (SPSS Inc., Chicago, IL, USA). The figures were constructed by MedCalc, version 15, or GraphPad Prism 8 . The results were expressed as means with standard deviation (SD) for normally distributed continuous variables, median values (interquartile ranges, IQR) for nonnormally distributed continuous variables, or frequencies and percentages for categorical variables. The unmeasured results were regarded as deficiency. The patients lost to follow-up were excluded in this retrospective cohort study. Student's $t$-test for independent samples was used for comparisons of normally distributed continuous variables. Comparisons of non-normally distributed continuous variables were performed using Mann-Whitney U-test. The Chi-square test was used for categorical variables. The receiver operating characteristic (ROC) curves were used to analyze predictors for ESRD, and the cut-off value was calculated by the maximum of the Youden index (sensitivity + specificity-1). The renal survival was established by Kaplan-Meier curves, and differences in survival rates were assessed with the log-rank test. The risk factors for ESRD were examined via Cox proportional hazards models. Variables statistically significant in univariate analyses entered into multivariate Cox models. A $\mathrm{P}$ value $<0.05$ was considered statistically significant.

\section{Results}

\section{The characteristics and MBL levels of DN patients with different renal outcome}

The baseline clinical characteristics of the DN patients were shown in Table 1 . Their average age was $52 \pm 10$ years and their median duration of diabetes history was 9.0 (4.0, $12.5)$ years. In a median follow-up duration of 28.0 (18.5, 40.0) months after renal biopsy, 33 (42.86\%) patients developed ESRD. The patients were divided into ESRD group (33 patients) and non-ESRD group (44 patients). The patients in ESRD group had more males, higher diastolic blood pressure, serum creatinine and urine protein levels, and lower serum albumin, hemoglobin and eGFR levels compared with the patients in non-ESRD group. The patients in ESRD group also had a shorter follow-up duration and lower percentage of angiotensin-converting 
Table 1 The baseline clinical characteristics in DN patients

\begin{tabular}{|c|c|c|c|c|}
\hline Variables & All & ESRD & Non-ESRD & $P$ value \\
\hline Gender, male, n (\%) & $51(66.23)$ & $26(78.79)$ & $25(56.82)$ & 0.04 \\
\hline Age (years) & $52 \pm 10$ & $51 \pm 10$ & $53 \pm 10$ & 0.32 \\
\hline Known duration of diabetes, median (IQR) (years) & $9.0(4.0,12.5)$ & $10.0(4.0,11.5)$ & $6.5(3.25,13.0)$ & 0.60 \\
\hline Systolic blood pressure $(\mathrm{mmHg})$ & $144 \pm 17$ & $145 \pm 18$ & $142 \pm 16$ & 0.47 \\
\hline Diastolic blood pressure $(\mathrm{mmHg})$ & $85 \pm 11$ & $88 \pm 10$ & $83 \pm 10$ & 0.03 \\
\hline Hemoglobin (g/L) & $108.25 \pm 19.70$ & $101.39 \pm 18.77$ & $113.39 \pm 19.00$ & $<0.01$ \\
\hline $\mathrm{HbA1c}(\%)$ & $7.76 \pm 2.04$ & $8.05 \pm 2.02$ & $7.33 \pm 2.04$ & 0.15 \\
\hline Low-density lipoprotein (mmol/L) & $2.83 \pm 1.38$ & $2.58 \pm 1.22$ & $3.02 \pm 1.48$ & 0.19 \\
\hline High-density lipoprotein (mmol/L) & $1.16 \pm 0.37$ & $1.18 \pm 0.39$ & $1.16 \pm 0.36$ & 0.80 \\
\hline Urinary protein $(\mathrm{g} / \mathrm{gCr})$ & $4.33 \pm 2.97$ & $5.88 \pm 2.91$ & $3.24 \pm 2.52$ & $<0.01$ \\
\hline Serum creatinine $(\mu \mathrm{mol} / \mathrm{L})$ & $124.07 \pm 54.91$ & $148.74 \pm 61.81$ & $105.56 \pm 40.84$ & $<0.01$ \\
\hline Serum urea nitrogen $(\mathrm{mmol} / \mathrm{L})$ & $8.63 \pm 3.49$ & $9.46 \pm 3.30$ & $8.00 \pm 3.54$ & 0.07 \\
\hline eGFR $\left(\mathrm{mL} / \mathrm{min} / 1.73 \mathrm{~m}^{2}\right)$ & $61.66 \pm 24.92$ & $51.66 \pm 21.31$ & $69.17 \pm 25.00$ & $<0.01$ \\
\hline CRP, median (IQR) (mg/L) & $2.25(1.40,3.32)$ & $2.70(1.70,4.20)$ & $2.20(1.40,3.30)$ & 0.30 \\
\hline ACEl/ARB use, $n(\%)$ & 59 (76.62) & $19(57.57)$ & $40(90.91)$ & $<0.01$ \\
\hline
\end{tabular}

DN, diabetic nephropathy; ESRD, end-stage renal disease; IQR, interquartile range; eGFR, estimated glomerular filtration rate; CRP, C-reactive protein; ACEI/ARB, angiotensin-converting enzyme inhibitor/angiotensin II receptor blocker; CCB, calcium channel blocker.

enzyme inhibitor (ACEI)/angiotensin II receptor blocker (ARB) usage. The renal pathological characteristics in both groups were shown in Table 2. The patients in ESRD group had a higher grade of IFTA than those in nonESRD group $(\mathrm{P}<0.05)$; however, there were no significant differences in glomerular lesions, interstitial inflammation, or arteriosclerosis between the two groups.

The median (IQR) serum MBL level was substantially higher in ESRD group than that in the non-ESRD group $[2,783.75(1,244.28,3,837.07)$ vs. $1,141.60$ (652.67, $3,188.44) \mathrm{ng} / \mathrm{mL}, \mathrm{P}=0.016$, Figure $2 A]$. Seventy-two out of the 77 patients had available urine samples. We then measured urine MBL level (normalized for urinary creatinine concentration) and found urine MBL level was also higher in ESRD group than that in non-ESRD group [1.02 (0.43,
2.05) vs. $0.27(0.04,0.58) \mathrm{ng} / \mathrm{mg}, \mathrm{P}<0.01$, Figure $2 B]$. The cut-off values based on the maximum value of the Youden index in ROC analysis were serum MBL $>1,108.75 \mathrm{ng} / \mathrm{mL}$ (Figure $3 A$ ) and urine $\mathrm{MBL}>0.61 \mathrm{ng} / \mathrm{mg}$ (Figure $3 B$ ) for prediction of ESRD. By univariate Cox analysis, shown in Table 3, serum MBL $>1,108.75 \mathrm{ng} / \mathrm{mL}$ and urine MBL $>0.61 \mathrm{ng} / \mathrm{mg}$ were risk factors for ESRD [hazard ratio (HR) $=4.164,95 \%$ CI: $1.601-10.833, \mathrm{P}=0.003 ; \mathrm{HR}=5.337,95 \%$ CI: $2.332-12.214, \mathrm{P}<0.001$, respectively]. Adjusted by the characteristics of urine MBL, diastolic blood pressure, hemoglobin, urinary protein, eGFR, and the classification of IFTA, ACEI/ARB usage, serum MBL >1,108.75 ng/mL remained an independent risk factor for ESRD $[\mathrm{HR}=4.644$, 95\% CI: $1.320-16.337, \mathrm{P}=0.017]$ by multivariate Cox analysis. 
Table 2 Renal pathological findings in the DN patients

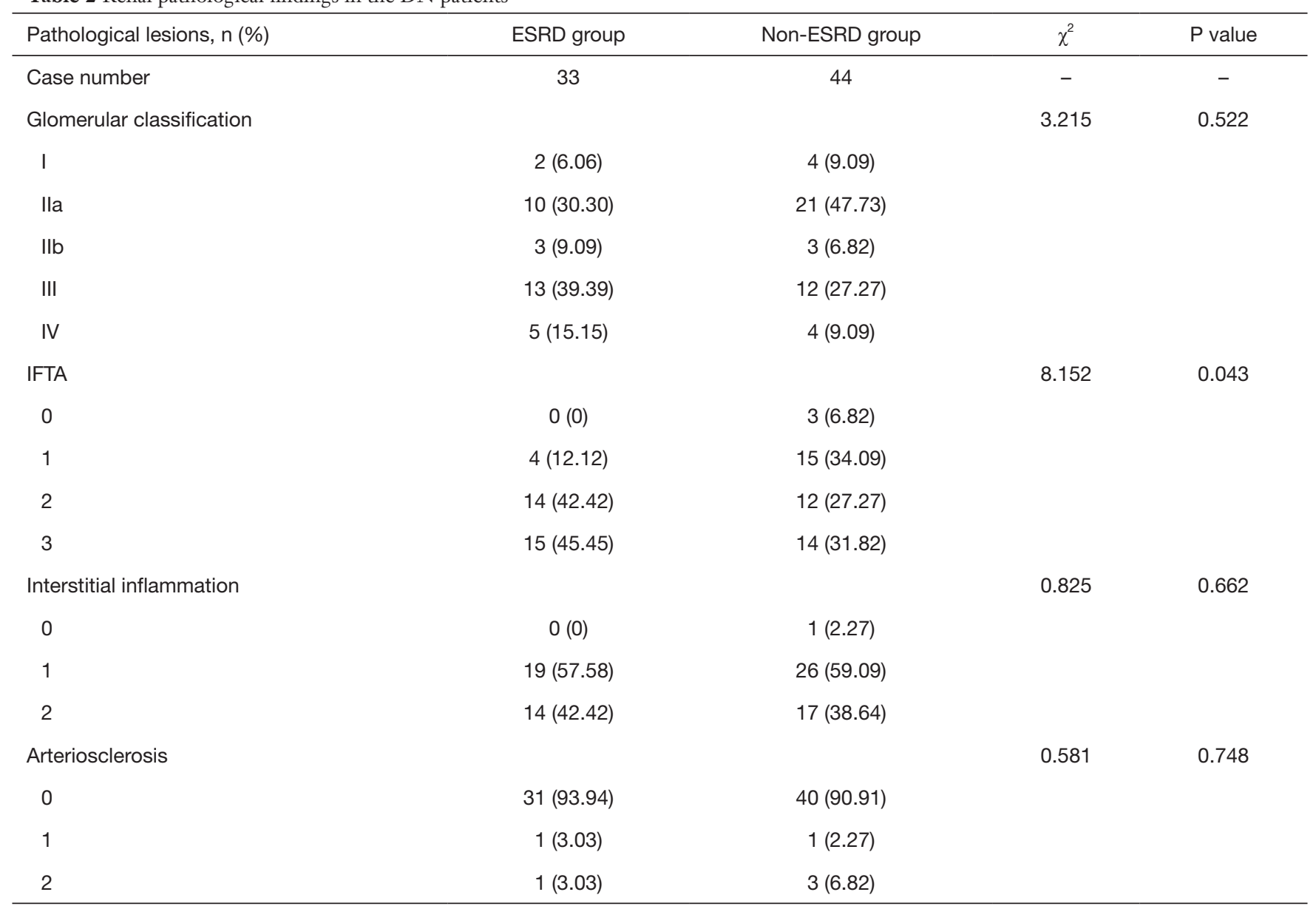

DN, diabetic nephropathy; ESRD, end-stage renal disease; IFTA, interstitial fibrosis and tubular atrophy.

\section{The SNPs of MBL2 gene in DN patients with different MBL levels}

The $77 \mathrm{DN}$ patients were divided low serum MBL group (serum $M B L \leq 1,108.75 \mathrm{ng} / \mathrm{mL}$ ) and high serum MBL group (serum MBL $>1,108.75 \mathrm{ng} / \mathrm{mL}$ ) by the cut-off value of serum MBL. The median serum MBL was 542.02 (265.01, 783.02) $\mathrm{ng} / \mathrm{mL}$ in low serum MBL group, and $3,136.78(2,023.80,3,881.09) \mathrm{ng} / \mathrm{mL}$ in high serum $\mathrm{MBL}$ group $(\mathrm{P}<0.01)$. Five $(6.84 \%)$ patients in low serum $\mathrm{MBL}$ group and $28(38.35 \%)$ patients in high serum MBL group reached ESRD during follow-up. Kaplan-Meier survival analysis showed that the renal survival rate was higher in low serum MBL group than that in high serum MBL group (log rank $=10.177, \mathrm{P}<0.01$ ) (Figure $4 A$ ). Also, 72 patients with urine $M B L$ results were divided into low urine MBL group (urine $\mathrm{MBL} \leq 0.61 \mathrm{ng} / \mathrm{mg}$ ) and high urine MBL group (urine MBL $>0.61 \mathrm{ng} / \mathrm{mg}$ ) by the cut-off value of urine MBL.
The median urine MBL level was $0.14(0.03,0.37) \mathrm{ng} / \mathrm{mg}$ in low urine MBL group, and $1.60(0.96,2.28) \mathrm{ng} / \mathrm{mg}$ in high urine MBL group $(\mathrm{P}<0.01)$. Eight $(11.11 \%)$ patients in low urine MBL group and 21 (29.16\%) patients in high urine MBL group developed ESRD. Kaplan-Meier survival analysis showed that renal survival rate was higher in low urine MBL group than that in the high urine MBL group $(\log$ rank $=19.569, \mathrm{P}<0.01)$ (Figure 4B).

The distribution of the genotype of $M B L 2$ SNPs in groups of patients with different serum or urine MBL levels was shown in Table 4. For SNP rs1800450, the frequencies of homozygous genotype (GG) and heterozygous genotype (GA) were different between high serum MBL group and low serum MBL group $(\mathrm{P}<0.01)$; whereas the frequencies were similar between high urine MBL group and low urine MBL group $(\mathrm{P}=0.52)$. For SNP rs11003125, rs7096206, and rs7095891, the frequencies were similar in both groups with 

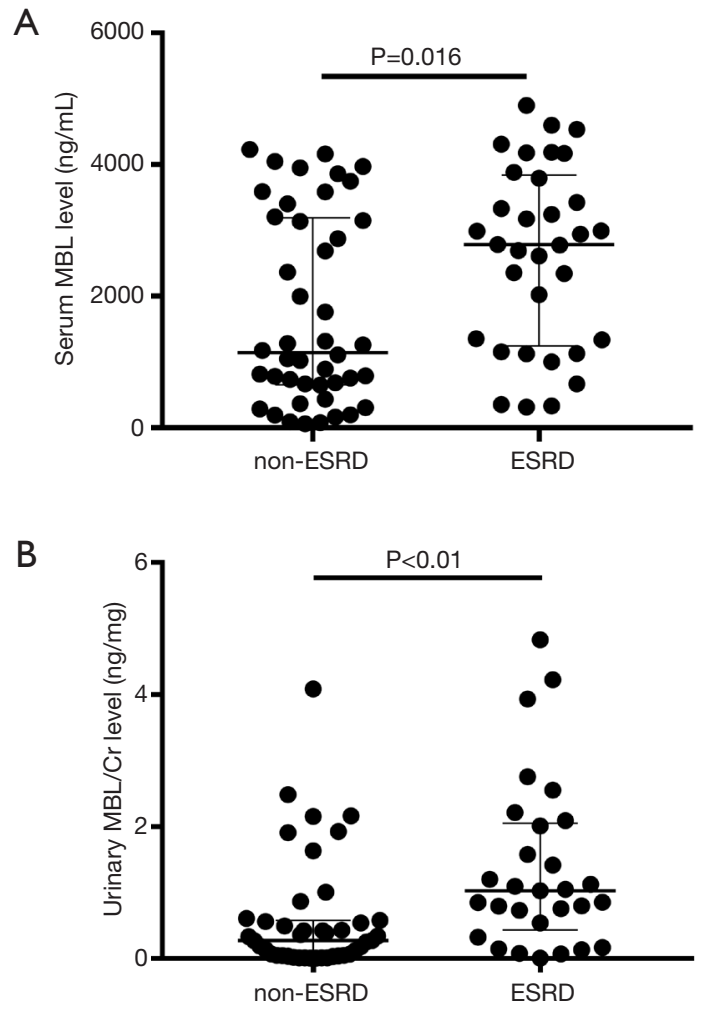

Figure 2 The serum (A) and urine (B) levels of MBL in DN patients. MBL, mannose-binding lectin; ESRD, end-stage renal disease; Cr, creatinine; DN, diabetic nephropathy.

different serum or urine MBL levels.

Patients with rs1800450 GG genotype had a higher serum MBL level (median 2,963.52 ng/mL) compared with those with GA genotype (median $665.38 \mathrm{ng} / \mathrm{mL})(\mathrm{Z}=-5.092$, $\mathrm{P}<0.001$ ) (Figure $5 A$ ). However, the urine MBL level was not statistically different between patients with rs 1800450 GG genotype and GA genotype (Figure 5B).

\section{The validation of the SNPs in the MBL2 gene in DN patients with different outcomes}

In order to validate the correlation of MBL2 SNPs with clinical outcomes, we retrospectively enrolled a new cohort of $133 \mathrm{DN}$ patients with the same inclusion and exclusion criteria as the previous cohort. These patients were admitted in our hospital from March 2005 to March 2018 and SNPs were analyzed. They had no serum or urine samples available. The baseline characteristics of these patients were shown in Tables S1,S2. The MBL2 SNPs of rs7096206, rs11003125, rs1800450, and rs7095891 were

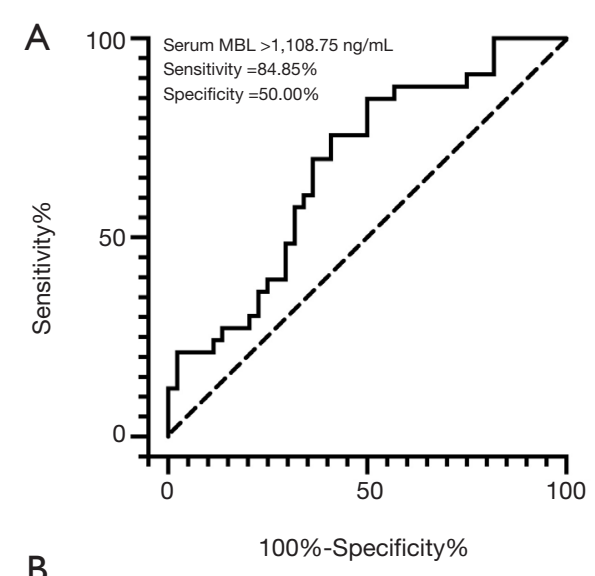

B

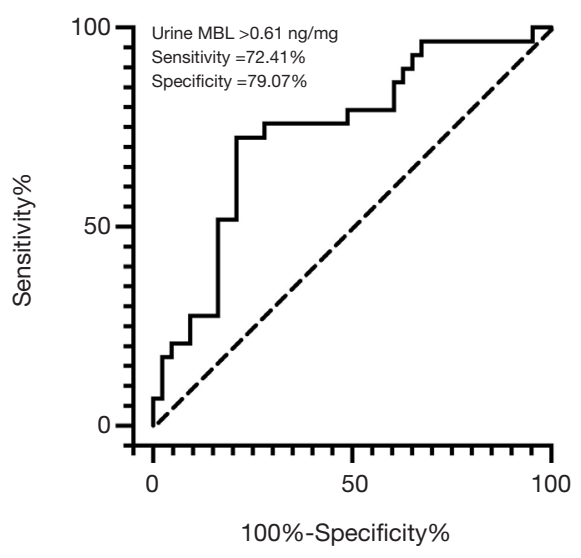

Figure 3 Receiver operating characteristic curve analysis using serum MBL levels (A) and urine MBL levels (B) at baseline for prediction of end stage renal disease in DN patients. MBL, mannose-binding lectin; DN, diabetic nephropathy.

shown in Table 5. There were 58 (43.61\%) patients in ESRD group and 75 (56.39\%) patients in non-ESRD group. The patients in non-ESRD group showed a tendency of higher frequency of rs1800450 GA genotype than that in ESRD group ( $\mathrm{P}=0.053)$. Furthermore, rs1800450 GA genotype was proven an independent protective factor for ESRD (HR $=0.485,95 \%$ CI: $0.237-0.991, \mathrm{P}=0.047$ ) by multivariate $\mathrm{Cox}$ analysis, adjusted by the characteristics of diastolic blood pressure, hemoglobin, eGFR, and the classification of IFTA, interstitial inflammation and arteriosclerosis, and the $M B L 2$ SNPs of rs11003125, rs7096206, and rs7095891 (Table 6).

\section{Discussion}

This study showed that the serum and urine MBL levels were higher in DN patients who were prone to develop 
Table 3 The analysis of risk factors for ESRD by univariate Cox regression

\begin{tabular}{|c|c|c|c|}
\hline Factors & Stratification & $\mathrm{HR}(95 \% \mathrm{Cl})$ & $P$ value \\
\hline Diastolic blood pressure (mmHg) & $\geq 90$ & $2.395(1.202,4.775)$ & 0.013 \\
\hline Hemoglobin (g/L) & $<130$ (male), $<120$ (female) & $3.460(1.054,11.356)$ & 0.041 \\
\hline Urinary protein $(\mathrm{g} / \mathrm{gCr})$ & $>3.5$ & $4.668(1.997,10.908)$ & $<0.001$ \\
\hline eGFR $\left(\mathrm{mL} / \mathrm{min} / 1.73 \mathrm{~m}^{2}\right)$ & $<60$ & $2.480(1.200,5.125)$ & 0.014 \\
\hline ACEI/ARB use & Yes & $0.196(0.095,0.402)$ & $<0.001$ \\
\hline IFTA & Absent $=0 ;<25 \%=1 ; 25-50 \%=2 ;>50 \%=3$ & $1.636(1.055,2.536)$ & 0.028 \\
\hline Interstitial inflammation & $\begin{array}{c}\text { Absent }=0 \text {; infiltration only in relation to IFTA } \\
=1 ; \text { infiltration in area without IFTA }=2\end{array}$ & $1.139(0.593,2.187)$ & 0.696 \\
\hline Serum MBL $(\mathrm{ng} / \mathrm{mL})$ & $>1,108.75$ & $4.164(1.601,10.833)$ & 0.003 \\
\hline Urinary MBL/Cr (ng/mg) & $>0.61$ & $5.337(2.332,12.214)$ & $<0.001$ \\
\hline
\end{tabular}

Note: the MBL were stratified by the cut-off levels in serum and urine. ESRD, end-stage renal disease; HR, hazard ratio; Cl, confidence interval; $\mathrm{Cr}$, creatinine; eGFR, estimated glomerular filtration rate; ACEI/ARB, angiotensin-converting enzyme inhibitor/angiotensin II receptor blocker; MBL, mannose-binding lectin; IFTA, interstitial fibrosis and tubular atrophy.

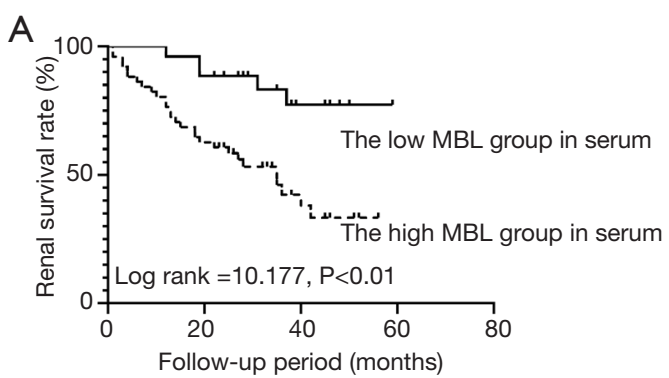

B

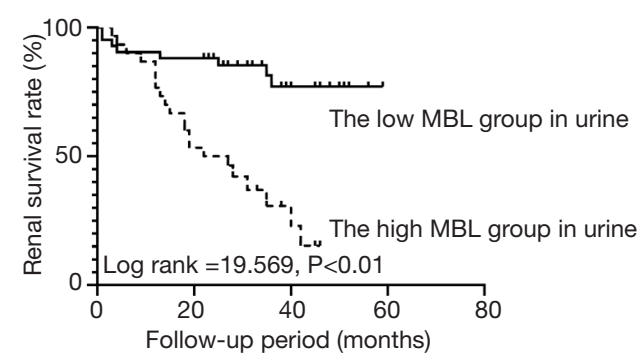

Figure 4 The cumulative renal survivals in two groups of DN patients categorized by serum MBL levels (A) and urine MBL levels (B) respectively, using the Kaplan-Meier method and log-rank test. MBL, mannose-binding lectin; DN, diabetic nephropathy.
ESRD, and serum MBL level was an independent risk factor for the progression to ESRD. In addition, the patients with GA genotype of rs1800450 of the MBL2 gene had lower serum MBL level and less possibility of developing ESRD.

Activation of MBL may initiate the regional and systemic inflammation through the cascade of complement and modulation of pro-inflammatory cytokine production (14). Studies showed increased plasma level of MBL was associated with the development of $\mathrm{DN}$ in patients with type $2 \mathrm{DM}$ $(8,9,15)$. Also, MBL and MBL-associated serine protease 1 (MASP1) deposited in the renal tubular interstitium, closely correlated with the severity of tubular interstitial injury $(8,16)$. Hansen et al. (17) reported that in type $2 \mathrm{DM}$ patients, measurement of MBL alone or in combination with C-reactive protein (CRP) can provide prognostic information on the development of albuminuria. Another study showed that elevated serum MBL in type 2 DM patients was correlated with the development of DN, especially in combination with serum CRP (18). MBL may also participate in the development of DN through oxidative stress and coagulation cascades $(19,20)$. These studies suggested that MBL may be involved in the mechanism of $\mathrm{DN}$ progression. We found that the elevated serum MBL level was an 
Table 4 The distribution of genotype of MBL2 SNPs in groups of patients with different MBL levels in serum or in urine

\begin{tabular}{|c|c|c|c|c|c|c|}
\hline Polymorphisms & \multicolumn{3}{|c|}{ Serum } & \multicolumn{3}{|c|}{ Urine } \\
\hline $\mathrm{N}$ & 25 & 48 & & 41 & 27 & - \\
\hline rs11003125, n (\%) & & & 0.05 & & & 0.96 \\
\hline GC & $7(28.00)$ & 25 (52.08) & & $18(43.90)$ & $12(44.44)$ & \\
\hline rs7096206, n (\%) & & & 0.13 & & & 0.52 \\
\hline $\mathrm{CC} / \mathrm{GG}$ & $15(60.00)$ & 37 (77.08) & & 29 (70.73) & 21 (77.78) & \\
\hline GC & $10(40.00)$ & $11(22.92)$ & & $12(29.27)$ & $6(22.22)$ & \\
\hline GA & $16(64.00)$ & $3(6.25)$ & & $12(29.27)$ & $6(22.22)$ & \\
\hline rs7095891, n (\%) & & & 0.90 & & & 0.87 \\
\hline $\mathrm{CC} / \mathrm{TT}$ & $20(80.00)$ & $39(81.25)$ & & 34 (82.93) & $22(81.48)$ & \\
\hline $\mathrm{TC}$ & $5(20.00)$ & $9(18.75)$ & & 7 (17.07) & $5(18.52)$ & \\
\hline
\end{tabular}

MBL, mannose-binding lectin; SNPs, single nucleotide polymorphisms.

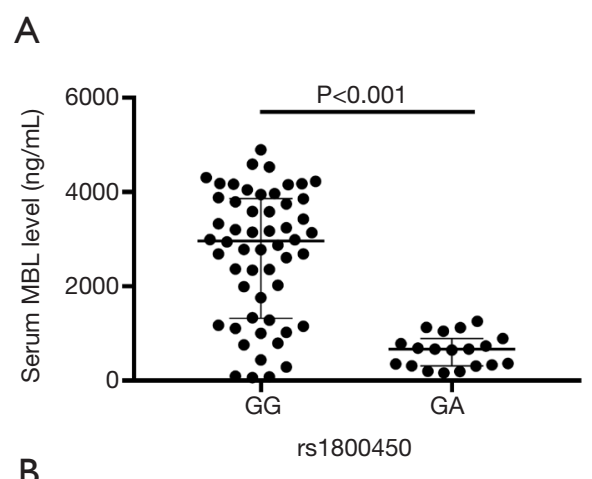

B

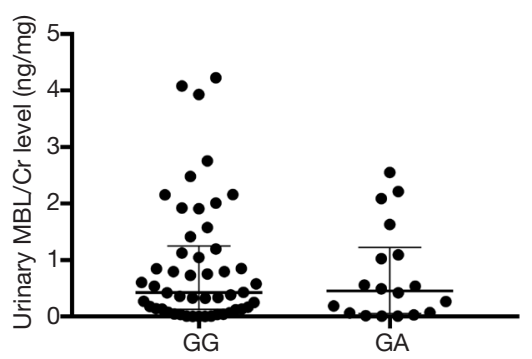

Figure 5 Distribution of serum MBL level (A) and urine MBL level (B) in study population stratified by gene variants of rs1800450. MBL, mannose-binding lectin; Cr, creatinine. independent risk factor for the progression to ESRD in DN patients, and the risk of ESRD was 4.644 assessed by HR when serum MBL was higher than $1,108.75 \mathrm{ng} / \mathrm{mL}$.

This study investigated the correlation of the MBL2 SNPs with DN progression, and further proved this correlation in a new cohort of DN patients. Bijkerk et al. demonstrated that circulating MBL levels were associated with DN, possibly being dependent on polymorphisms of the MBL2 exon 1 and promoter (21). Similarly, patients with the GA genotype of MBL2 rs1800450 gene had low serum MBL level in our study, consistent with the previous study (13). rs1800450 was the main variant in the exon 1 region of the $M B L 2$ gene and was shown to be associated with the development of type 2 diabetes (22). In Hansen's study, genotypes with high MBL expression were more frequent in DN patients than those with normal urinary albumin excretion (UAE), and the risk of having nephropathy was 1.52 assessed by odds ratio (OR) given a high MBL genotype (23). Our results indicated that DN patients with heterozygous genotype (GA) of rs1800450 had better renal outcomes than those with homozygous genotype, decreasing the HR of ESRD development in DN patients by $51.5 \%$. These results suggested that the 
Table 5 The distribution of MBL2 SNPs with different renal outcome in $133 \mathrm{DN}$ patients

\begin{tabular}{|c|c|c|c|c|c|}
\hline Polymorphisms & Total & ESRD group & Non-ESRD group & $\chi^{2}$ & $P$ value \\
\hline rs11003125, n (\%) & & & & 0.473 & 0.492 \\
\hline $\mathrm{CC} / \mathrm{GG}$ & 71 (53.38) & $29(50.00)$ & $42(56.00)$ & & \\
\hline GC & $62(46.62)$ & $29(50.00)$ & $33(44.00)$ & & \\
\hline $\mathrm{CC} / \mathrm{GG}$ & $101(75.94)$ & $42(72.41)$ & $59(78.67)$ & & \\
\hline GC & $32(24.06)$ & $16(27.59)$ & $16(21.33)$ & & \\
\hline rs1800450, n (\%) & & & & 3.744 & 0.053 \\
\hline $\mathrm{GG} / \mathrm{AA}$ & $99(74.44)$ & $48(82.76)$ & $51(68.00)$ & & \\
\hline $\mathrm{CC} / \mathrm{TT}$ & $112(84.21)$ & $50(86.21)$ & $62(82.67)$ & & \\
\hline TC & $21(15.79)$ & $8(13.79)$ & $13(17.33)$ & & \\
\hline
\end{tabular}

MBL, mannose-binding lectin; SNPs, single nucleotide polymorphisms; DN, diabetic nephropathy.

Table 6 The correlation between complement activation and renal outcome with respect to end-stage renal disease by the multivariate Cox regression in $133 \mathrm{DN}$ patients

\begin{tabular}{|c|c|c|c|}
\hline Factors & Stratification & $\mathrm{HR}(95 \% \mathrm{Cl})$ & $P$ value \\
\hline Hemoglobin, g/L & $<130$ (male), <120 (female) & $0.562(0.247,1.282)$ & 0.171 \\
\hline eGFR $\left(\mathrm{mL} / \mathrm{min} / 1.73 \mathrm{~m}^{2}\right)$ & $<60$ & $2.177(1.168,4.058)$ & 0.014 \\
\hline IFTA & Absent $=0 ;<25 \%=1 ; 25-50 \%=2 ;>50 \%=3$ & $1.702(1.099,2.637)$ & 0.017 \\
\hline Arteriosclerosis & $\begin{array}{c}\text { No intimal thickening }=0 \text {; intimal thickening less than } \\
\text { thickness of media }=1 \text {; intimal thickening greater than } \\
\text { thickness of media }=2\end{array}$ & $1.165(0.719,1.889)$ & 0.535 \\
\hline rs1800450 & GA & $0.485(0.237,0.991)$ & 0.047 \\
\hline rs7095891 & $\mathrm{TC}$ & $1.125(0.496,2.553)$ & 0.778 \\
\hline
\end{tabular}

DN, diabetic nephropathy; HR, hazard ratio; $\mathrm{Cl}$, confidence interval; eGFR, estimated glomerular filtration rate; IFTA, interstitial fibrosis and tubular atrophy.

GA genotype of rs1800450 may be valuable for predicting the incidence of ESRD in DN patients. In addition, no correlation was observed between the other gene SNPs and ESRD in the present study, which is consistent with the previous study by Zhang et al. (13)

In conclusion, activation of MBL was correlated with the progression of DN. The rs1800450 SNP of the MBL2 gene may be valued in predicting the incidence of ESRD 
in DN patients. Considering the limitations of this study as a single-center study with a small sample size, the role of MBL in DN pathogenesis needs to be further confirmed.

\section{Acknowledgments}

Funding: This study was supported by the funds from National Key R\&D Program of China (2018YFC1314003), and National Natural Science Foundation of China (81570605, 81770674) to Fei Han.

\section{Footnote}

Reporting Checklist: The authors have completed the STROBE reporting checklist. Available at http://dx.doi. org/10.21037/atm-20-1073

Data Sharing Statement: Available at http://dx.doi. org/10.21037/atm-20-1073

Conflicts of Interest: All authors have completed the ICMJE uniform disclosure form (available at http://dx.doi. org/10.21037/atm-20-1073). The authors have no conflicts of interest to declare.

Ethical Statement: The authors are accountable for all aspects of the work in ensuring that questions related to the accuracy or integrity of any part of the work are appropriately investigated and resolved. This research protocols were conformed to the provisions of the Declaration of Helsinki (as revised in 2013) and were approved by the Ethic Committee of the First Affiliated Hospital of Medical School of Zhejiang University (No. 2017243). All patients were informed consent.

Open Access Statement: This is an Open Access article distributed in accordance with the Creative Commons Attribution-NonCommercial-NoDerivs 4.0 International License (CC BY-NC-ND 4.0), which permits the noncommercial replication and distribution of the article with the strict proviso that no changes or edits are made and the original work is properly cited (including links to both the formal publication through the relevant DOI and the license). See: https://creativecommons.org/licenses/by-nc-nd/4.0/.

\section{References}

1. Webster AC, Nagler EV, Morton RL, et al. Chronic
Kidney Disease. Lancet 2017;389:1238-52.

2. Popat RJ, Robson M. Complement and glomerular diseases. Nephron Clin Pract 2014;128:238-42.

3. Klessens CQF, Zandbergen M, Wolterbeek R, et al. Macrophages in diabetic nephropathy in patients with type 2 diabetes. Nephrol Dial Transplant 2017;32:1322-9.

4. Moon JY, Jeong KH, Lee TW, et al. Aberrant recruitment and activation of $\mathrm{T}$ cells in diabetic nephropathy. Am J Nephrol 2012;35:164-74.

5. Nguyen D, Ping F, Mu W, et al. Macrophage accumulation in human progressive diabetic nephropathy. Nephrology 2006;11:226-31.

6. Dommett RM, Klein N, Turner MW. Mannose-binding lectin in innate immunity: past, present and future. Tissue Antigens 2006;68:193-209.

7. Ip WK, Takahashi K, Ezekowitz RA, et al. Mannosebinding lectin and innate immunity. Immunol Rev 2009;230:9-21.

8. Zheng JM, Ren XG, Jiang ZH, et al. Lectin-induced renal local complement activation is involved in tubular interstitial injury in diabetic nephropathy. Clin Chim Acta 2018;482:65-73.

9. Li XQ, Chang DY, Chen M, et al. Complement activation in patients with diabetic nephropathy. Diabetes Metab 2019;45:248-53.

10. Bus P, Chua JS, Klessens CQF, et al. Complement Activation in Patients With Diabetic Nephropathy. Kidney Int Rep 2017;3:302-13.

11. American Diabetes Association. Standards of Medical Care in Diabetes-2017 Abridged for Primary Care Providers. Clin Diabetes 2017;35:5-26.

12. Tervaert TW, Mooyaart AL, Amann K, et al. Pathologic classification of diabetic nephropathy. J Am Soc Nephrol 2010;21:556-63.

13. Zhang N, Zhuang M, Ma A, et al. Association of levels of mannose-binding lectin and the MBL2 gene with type 2 diabetes and diabetic nephropathy. PLoS One 2013;8:e83059.

14. Collard CD, Väkevä A, Morrissey MA, et al. Complement activation after oxidative stress: role of the lectin complement pathway. Am J Pathol 2000;156:1549-56.

15. Guan LZ, Tong Q, Xu J. Elevated serum levels of mannose-binding lectin and diabetic nephropathy in type 2 diabetes. PLoS One 2015;10:e0119699.

16. Huang $\mathrm{Y}, \mathrm{Xu} \mathrm{J}, \mathrm{Wu} \mathrm{X}$, et al. High Expression of Complement Components in the Kidneys of Type 2 Diabetic Rats with Diabetic Nephropathy. Front Endocrinol (Lausanne) 2019;10:459. 
17. Hansen TK, Gall MA, Tarnow L, et al. Mannose-binding lectin and mortality in type 2 diabetes. Arch Intern Med 2006;166:2007-13.

18. Elawa G, AoudAllah AM, Hasaneen AE, et al. The predictive value of serum mannan-binding lectin levels for diabetic control and renal complications in type 2 diabetic patients. Saudi Med J 2011;32:784-90.

19. Pan HZ, Zhang L, Guo MY, et al. The oxidative stress status in diabetes mellitus and diabetic nephropathy. Acta Diabetol 2010:71-6.

20. Aso Y, Yoshida N, Okumura K, et al. Coagulation and inflammation in overt diabetic nephropathy: association with hyperhomocysteinemia. Clin Chim Acta 2004;348:139-45.

Cite this article as: Cai K, Ma Y, Wang J, Nie W, Guo J, Zhang M, Yang Y, Chen J, Han F. Mannose-binding lectin activation is associated with the progression of diabetic nephropathy in type 2 diabetes mellitus patients. Ann Transl Med 2020;8(21):1399. doi: 10.21037/atm-20-1073
21. Bijkerk R, van der Pol P, Khairoun M, et al. Simultaneous pancreas-kidney transplantation in patients with type 1 diabetes reverses elevated MBL levels in association with MBL2 genotype and VEGF expression. Diabetologia 2016;59:853-8.

22. Muller YL, Hanson RL, Bian L, et al. Functional variants in MBL2 are associated with type 2 diabetes and prediabetes traits in Pima Indians and the old order Amish. Diabetes 2010;59:2080-5.

23. Mellbin LG, Hamsten A, Malmberg K, et al. Mannosebinding lectin genotype and phenotype in patients with type 2 diabetes and myocardial infarction: a report from the DIGAMI 2 trial. Diabetes Care 2010;33:2451-6. 